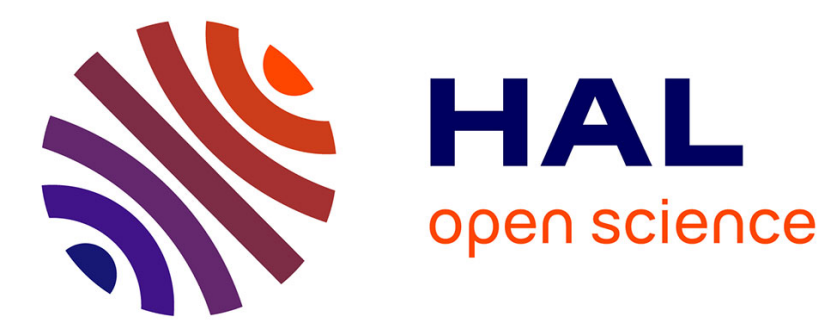

\title{
Temperature and LET effects on radiation-induced modifications in non-perfect polyethylenes
}

K. Furtak-Wrona, M. Cornaton, D. Durand, V. Dauvois, J.-L. Roujou, S. Esnouf, M. Ferry

\section{- To cite this version:}

K. Furtak-Wrona, M. Cornaton, D. Durand, V. Dauvois, J.-L. Roujou, et al.. Temperature and LET effects on radiation-induced modifications in non-perfect polyethylenes. Polymer Degradation and Stability, 2019, 162, pp.66 - 75. 10.1016/j.polymdegradstab.2019.02.002 . hal-03485993

\section{HAL Id: hal-03485993 https://hal.science/hal-03485993}

Submitted on 20 Dec 2021

HAL is a multi-disciplinary open access archive for the deposit and dissemination of scientific research documents, whether they are published or not. The documents may come from teaching and research institutions in France or abroad, or from public or private research centers.
L'archive ouverte pluridisciplinaire HAL, est destinée au dépôt et à la diffusion de documents scientifiques de niveau recherche, publiés ou non, émanant des établissements d'enseignement et de recherche français ou étrangers, des laboratoires publics ou privés.

\section{다(1) $\$$}

Distributed under a Creative Commons Attribution - NonCommercial| 4.0 International 
1 Temperature and LET effects on radiation-induced modifications in non-perfect

2

3

\section{polyethylenes}

\author{
K. Furtak-Wrona' ${ }^{1}$, M. Cornaton ${ }^{1}$, D. Durand ${ }^{1}$, V. Dauvois ${ }^{1}$, J.-L. Roujou ${ }^{1}$, S. Esnouf ${ }^{1}$ and M. Ferry ${ }^{1}$ \\ ${ }^{1}$ Den-Service d’Étude du Comportement des Radionucléides (SECR), CEA, Université Paris- \\ Saclay, Gif-sur-Yvette, France.
}

\section{Abstract}

Regarding the nuclear safety, the potential accumulation of explosive gases during storage, transport and final disposal of Intermediate Level Long Lived Wastes (IL-LLW) has to be well understood and precisely evaluated. In this paper, we have investigated the Linear Energy Transfer (LET) effect that takes into account the different emitters present in the packages, but also the temperature impact in transport safety cases. We have focused our study on polyethylene, as this polymer presents one of the highest hydrogen radiation chemical yield $\left(\mathrm{G}_{0}\left(\mathrm{H}_{2}\right)\right)$, and because of the explosive and inflammable nature of this gas. Chemical defects included in the polymer in the form of carbonyl $(\mathrm{C}=0)$ and vinyl $(\mathrm{C}=\mathrm{C})$ groups were explored. Depending on the atmosphere of irradiation, they are the main defects formed in polyethylene under irradiation and they are known to be effective energy and radical scavengers. Characterization of the chemical structure of pristine materials has been done. Hydrogen radiation chemical yields were quantified after polymers irradiation. Additionally, the carbon monoxide release was measured for polyethylenes with $\mathrm{C}=0$ moieties. Whatever the type of double bonds present in the polymer and whatever the irradiation conditions, hydrogen emission decreases compared to neat materials. Double bonds are effective scavenging groups to which energy is transferred regardless the irradiation nature. Underlying phenomena are explained in this work.

\section{Keywords}

Radiation chemical yields; hydrogen; polyethylenes; defects influence; LET effect; irradiation temperature impact 


\section{Introduction}

The Intermediate Level Long Lived Waste (IL-LLW) packages contain technological waste resulting from the maintaining, operating or dismantling phases of nuclear installations and research laboratories. In such containers, polymers can be found in the form of gloves, filters, cables, seals or bottles and so on. During their whole use they have been in the contact with artificial radioactivity, hence they cannot be thrown in garbage as conventional waste at the end of their life. Once placed inside the IL-LLW packages, these polymers are still subjected to the action of $\gamma, \beta$, and $\alpha$ emitters coming from radioactive elements also located in these containers. In contact with the actinides, molecular changes can occur in these materials and cause such modifications as polymer backbone scission or crosslinking, gas emission and formation of new chemical bonds [1-3].

As three kinds of emitters are present in the IL-LLW containers, the LET impact on the gas emission rates has to be understood. The main effect of LET is to exacerbate the heterogeneity of energy deposition and to increase the local concentration of primary radiolytic products. Chang and LaVerne [4] have shown that the radiation chemical yield of hydrogen increases with LET raising. Moreover, these authors have investigated the effect of chemical structure of polymers (polyethylene PE, polypropylene PP, poly(methyl methacrylate) PMMA and polystyrene PS) on the relative change in hydrogen yield as a function of LET. They have found that at low LET, $G\left(H_{2}\right)_{P E} \sim G\left(H_{2}\right)_{P P} \sim 10 \cdot G\left(H_{2}\right)_{P M M A} \sim 100 \cdot G\left(H_{2}\right)_{P S}$. In the case of PMMA and PS, the low yields were assigned to their carbonyl and aromatic side groups, known to be effective radical scavengers [5-10]. When LET increases from 0.02 to $9.5 \mathrm{MeV} \cdot \mathrm{mg}^{-1} \cdot \mathrm{cm}^{2}$, hydrogen yields are increasing, but the relative increase depends on the material under study: a factor of about 2 for polyolefins (PE and PP), about 10 for PMMA and about 30 in the case of PS has been observed by the researchers between the lowest and the highest yields.

In France, the IL-LLW containers are designed for a foreseen deep geological disposal. However, before this final step they need to be transported by road. In order to take into account all the probable risk of accident, the French Nuclear Safety Authority requests to take into account an accident with a resulting fire that might last 24 hours. The temperature inside the waste containers can increase in these conditions up to $150{ }^{\circ} \mathrm{C}$. As many reactions are thermally activated, this parameter has already been evaluated.

Hence, Arai et al. [11] have shown that during the radiolysis of methane at low dose rate, the hydrogen radiation chemical yield rises together with the temperature from $-78{ }^{\circ} \mathrm{C}$ to $495{ }^{\circ} \mathrm{C}$. The effect of gamma irradiation temperature on gas production in inert atmosphere was studied on polyethylene by Wu et al., Seguchi, Mitsui et al., Kang et al., and Bowmer et al. [12-16]. These 
researchers have confirmed in a consistent way that hydrogen emission increases with temperature raising from room temperature up to $300{ }^{\circ} \mathrm{C}$. However, below $150{ }^{\circ} \mathrm{C}$ that corresponds to the melting point of polyethylene, the data show two types of behavior depending on the studies. Either hydrogen radiation chemical yield is constant up to a temperature threshold between 60 and $80{ }^{\circ} \mathrm{C}$ and then increases, or it increases whenever the irradiation temperature exceeds the room temperature.

Last but not least parameter to take into account in the IL-LLW packages safety is the polymers evolution with the high doses that are encountered in such conditions. When dose is increasing, whatever the atmosphere to be considered, double bonds are formed. Carbonyl groups are the main new bonds created under oxidative atmosphere, whereas vinylene linkages are the main defects formed under inert atmosphere. These two kinds of bonds are known to be effective scavengers. It can be supposed that with the dose increase, the concentration of energy scavengers will increase, and the gas emission will decrease. This is in agreement, at room temperature, with different works on alkanes as on macromolecules [17-19]. To the best of our knowledge, only Williams et al. [20] have analyzed the influence of the irradiation temperature on the stabilization of polyethylene by double bonds. They have irradiated a few mixtures of low-density polyethylene and polybutadiene, and have demonstrated that the protective role of double bonds becomes more important when irradiation temperature rises.

In this work, we have studied polyethylenes (PE) with specific defects to evaluate the Linear Energy Transfer (LET) and the temperature effects on the energy and radical migration. We focus in this article on the impact of chemical structure and defects which are present in polymer chain $(\mathrm{C}=\mathrm{C}$ and $\mathrm{C}=0$ groups). These double bonds were chosen because they are representative of main degradation products, and they are effective energy scavengers. In order to determine their ability to decrease the gas emission radiation chemical yields depending on the irradiation conditions, we have examined the effect of their position (in the polymer backbone or as a pendant groups for $\mathrm{C}=\mathrm{C}$ bonds) and of their concentration (for $\mathrm{C}=0$ bonds).

\section{Experimental}

\subsection{Materials}

The polymers used in this work were commercially available polyethylenes or materials obtained from the research laboratories. They were "neat" or almost perfect (PE 181900, PE Goodfellow, PE GURa), or contain defects such as carbonyl groups (PE 427780, PE 427772) or $\mathrm{C}=\mathrm{C}$ double bonds (MB150, EPDMh). Their designations and in some cases their average 
molecular weights given by the suppliers are summarized in Table 1. A first part of this article will be dedicated to their characterization prior to irradiation.

101

102 Table 1. Characteristics of polyethylene and aliphatic polymers. $M_{n}$ and $M_{w}$ are the number average molecular mass and the mass average molar mass, respectively. "-“ : absence of value.

\begin{tabular}{|c|c|c|c|c|c|c|}
\hline & $\begin{array}{l}\text { Polymer } \\
\text { designation }\end{array}$ & Supplier & $\begin{array}{l}\text { Reference } \\
\text { number }\end{array}$ & Form & $M_{n}\left(g \cdot m^{-1}\right)$ & $\mathrm{M}_{\mathrm{w}}\left(\mathrm{g} \cdot \mathrm{mol}^{-1}\right)$ \\
\hline \multirow{3}{*}{$\begin{array}{c}\text { Perfect } \\
\text { polyethylenes }\end{array}$} & PE 181900 & $\begin{array}{l}\text { Sigma- } \\
\text { Aldrich }\end{array}$ & 181900 & Pellets & - & 125000 \\
\hline & PE Goodfellow & Goodfellow & & Film & - & - \\
\hline & PE GURa & $\mathrm{OBBL}^{1}$ & & Cut pieces & - & - \\
\hline \multirow{2}{*}{$\begin{array}{c}\text { PE with } \mathrm{C}=\mathrm{C} \\
\text { defects }\end{array}$} & MB150 & $\mathrm{LCPP}^{2}$ & & Powder & 10900 & 21800 \\
\hline & EPDMh & Nordel & 2722 & Film & $36000[21]$ & $254000[21]$ \\
\hline \multirow{2}{*}{$\begin{array}{c}\text { PE with } C=0 \\
\text { defects }\end{array}$} & PE 427780 & $\begin{array}{l}\text { Sigma- } \\
\text { Aldrich }\end{array}$ & 427780 & Pellets & 5500 & 15000 \\
\hline & PE 427772 & $\begin{array}{l}\text { Sigma- } \\
\text { Aldrich }\end{array}$ & 427772 & Powder & 1700 & 4000 \\
\hline
\end{tabular}

104

105 These materials were chosen for the perfection or for the defects they can present. Three neat

106 polyethylenes were considered as references. Methylene based polymers with $\mathrm{C}=\mathrm{C}$ defects were

107 chosen because of the position of the double bonds: in the backbone or on the side-chain, which

108 is of great interest to understand the preferential paths of migration of energy and radicals.

109 Finally, polyethylenes 427780 and 427772 , supposed to be neat ones, were initially chosen

110 because of their different molecular weights. However, after FTIR analysis (see section 3.3), C=0

111 bonds were found in both materials. As this kind of double bond is the main defect formed in

112 polyethylenes under radio-oxidation [25], we found these two polymers of great interest.

\section{$114 \quad 2.2 \quad$ Irradiation conditions}

\section{$115 \quad 2.2 .1 \quad$ Sample preparation}

116 Each specimen of polymer was placed in glass tube and evacuated by a vacuum line in order to 117 remove oxygen dissolved in the samples. Then, the glass container was filled with pure helium 118 gas under around $700 \mathrm{mbar}$ and sealed. For each sample/irradiation condition couple, two

${ }^{1}$ OBBL: Harris Orthopaedic Biomechanics and Biomaterials Laboratory (Massachusetts General Hospital, Boston, USA).

2 LCPP: Laboratoire de Chimie et de Procédés de Polymérisation (CNRS - UMR 140, ESCPE Lyon, Villeurbanne, France). 
ampoules were prepared, and irradiated at two different and relatively low doses. Sample weights were estimated to obtain, at the end of the irradiation, a final $\mathrm{H}_{2}$ content of about $1 \%$ vol.

\subsubsection{Gamma irradiations}

123 Gamma irradiations were performed at LABRA (CEA Saclay, France), with a ${ }^{60}$ Co source. 124 Dosimetry was performed using a UNIDOS PTW dosimeter equipped with a calibration chamber adjusted every two years by the CEA's LNHB laboratory (COFRAC certification): the ionization chamber was placed in air where the samples were put. No electronic correction was made to 127 take into account the electronic density difference between water and polymers. Uncertainties 128 on given doses are less than $6 \%$.

129 For the irradiations carried out at high temperature, glass containers were placed in a furnace, 130 which was positioned inside the irradiator. Temperature was increased up to the desired one, 131 then the irradiation was started and continued up to the desired dose.

132 At room temperature, dose rate was equal to $1.04 \mathrm{kGy} \cdot \mathrm{h}^{-1}$ and doses of the two glass containers 133 were $49.9 \mathrm{kGy}$ and $99.8 \mathrm{kGy}$, respectively. At $60-63{ }^{\circ} \mathrm{C}, 80^{\circ} \mathrm{C}$ and $100{ }^{\circ} \mathrm{C}$, dose rate was equal to $1341.09 \mathrm{kGy} \cdot \mathrm{h}^{-1}$ and the final dose was $26.1 \mathrm{kGy}$. Irradiations at $120^{\circ} \mathrm{C}$ and $150{ }^{\circ} \mathrm{C}$ were performed 135 with a dose rate of $1.00 \mathrm{kGy} \cdot \mathrm{h}^{-1}$ and a total dose of $24.0 \mathrm{kGy}$.

\subsubsection{Ion irradiations at room temperature}

Ions experiment was performed at Grand Accélérateur National d'Ions Lourds (GANIL, Caen, France). The high energy beamline was used due to the need to go through the ampoule glass walls without reducing drastically the energy of the beam reaching the samples placed inside the 141 glass ampoules.

142 Homogeneous irradiation was ensured by a $\mathrm{x}, \mathrm{y}$-scanned beam (surface of about $36 \mathrm{~cm}^{2}$ ). The 143 energy loss was calculated with $\mathrm{SRIM}^{3}$, based on the TRIM ${ }^{4}$ code [22]. Irradiation conditions are 144 gathered in Table 2. In order to avoid significant sample heating, fluxes were chosen in order to 145 limit the power deposition on the sample to $0.5 \mathrm{~mW} \cdot \mathrm{cm}^{-2}$.

146 Statistical errors for a given sample and for a single beam are low, at most a few percentage. The 147 systematic errors are higher, and are mainly caused by sample thickness and dose estimation, 148 because of the material composition changes. At the highest dose, the systematic error is less 149 than $10 \%$, so the total one on dose has been estimated at about $10 \%$.

\footnotetext{
${ }^{3}$ Stopping and Range of Ions in Matter.

4 Transport of Ions in Matter.
} 
151 Table 2. Irradiation conditions using the high energy beamline of GANIL.

\begin{tabular}{|c|c|}
\hline Beam & ${ }^{36} \mathrm{Ar}$ \\
\hline Initial particle energy $\left(\mathrm{MeV} \cdot \mathrm{A}^{-1}\right)$ & 95 \\
\hline Particle energy at the entrance of the polymer $\left(\mathrm{MeV} \cdot \mathrm{A}^{-1}\right)$ & 89 \\
\hline Flux $\left(10^{8} \mathrm{~cm}^{-2} \cdot \mathrm{s}^{-1}\right)$ & 3.4 \\
\hline Mean LET $\left(\mathrm{MeV} \cdot \mathrm{mg}^{-1} \cdot \mathrm{cm}^{2}\right)$ & 2.5 \\
\hline Mean dose rate $\left(\mathrm{kGy} \cdot \mathrm{h}^{-1}\right)$ & 500 \\
\hline Fluences $\left(10^{11} \mathrm{~cm}^{-2}\right)$ & 6.7 and 12.5 \\
\hline Doses (kGy) & 290 and 570 \\
\hline
\end{tabular}

152

\section{$153 \quad 2.3$ Characterizations}

\section{$154 \quad$ 2.3.1 Differential Scanning Calorimetry (DSC)}

155 Differential scanning calorimetry (DSC) measurements have been performed to determine 156 melting temperature and crystallinity, two parameters of great influence on the radiation157 induced mechanisms [3]. A Netzsch STA 449 Jupiter instrument was employed in inert 158 atmosphere (helium at a flow rate of $60 \mathrm{~mL} \cdot \mathrm{min}^{-1}$ ), with a temperature gradient of $5 \mathrm{~K} \cdot \mathrm{min}^{-1}$. 159 Melting temperature $\left(\mathrm{T}_{\mathrm{m}}\right)$ is defined as the temperature at the maximum of the melting 160 endothermic peak. Area of the melting peak, $\Delta H_{f}$, was measured and crystallinity, $\chi_{c}$, was 161 calculated using equation (S1) of the Supplementary Information (along with the crystallinity 162 data).

163

\section{$164 \quad$ 2.3.2 Fourier transform infrared spectroscopy (FTIR)}

165 Fourier Transform Infrared spectra of the polymers were acquired using a Bruker Vertex 70 166 spectrometer equipped with a DTGS (Deuterated TriGlycine Sulfate) detector. Spectra were 167 recorded between 4000 and $600 \mathrm{~cm}^{-1}$ at a resolution of $2 \mathrm{~cm}^{-1}$ and with 64 accumulated scans.

168 In most cases, samples were analyzed in Attenuated Total Reflectance (ATR mode) with a Specac 169 Golden Gate single reflection diamond accessory. This technique is chosen for its easiness of use, 170 as no sample preparation is needed. Moreover, it gives significant information on the molecular 171 bond nature evolution under irradiation. 
172 To discriminate if the carbonyl bonds are present on impurities or on the polymer backbone in 173 polyethylenes containing $\mathrm{C}=0$ bonds (see section 3.3), experiments were realized in 174 transmission mode. In that specific case, about $10 \mathrm{mg}$ of polymer was mixed with $150 \mathrm{mg} \mathrm{of} \mathrm{KBr}$ 175 and pellets were formed using a laboratory press.

\subsubsection{Gas Chromatography coupled with Mass Spectrometry (GC-MS)}

178 Measurements were performed on an Agilent gas chromatography (GC-6890) coupled with a mass spectrometer (MS5973 N). About $1 \mu \mathrm{L}$ of polyethylene solubilized in dichloromethane was injected in splitless mode. The inlet temperature was at $250{ }^{\circ} \mathrm{C}$. Molecules were separated on a Sigma-Supelco SLB-MS column $30 \mathrm{~m} \times 0.25 \mathrm{~mm} \times 0.25 \mu \mathrm{m}$ and analyzed with a mass spectrometer equipped with an electron impact source, set at $230{ }^{\circ} \mathrm{C}$. The MS detector operated in scan mode over a mass-range of 50-300 amu.

184

185

186

187

188

The oven was stabilized at $40{ }^{\circ} \mathrm{C}$ for $5 \mathrm{~min}$, then a temperature gradient of $20^{\circ} \mathrm{C} \cdot \mathrm{min}^{-1}$ was applied up to $320^{\circ} \mathrm{C}$ and finally maintained at $320^{\circ} \mathrm{C}$ for $10 \mathrm{~min}$. Helium was used as the carrier gas at a flow rate of $1.5 \mathrm{~mL} \cdot \mathrm{min}^{-1}$.

\subsubsection{Gas analyses}

As irradiation was carried out under inert atmosphere, the form and the thickness of the samples are not critical parameters for ensuring a homogeneous energy deposition. However, in order to minimize the influence of gas diffusion inside the bulk material, no sample was thicker than $2 \mathrm{~mm}$. A simple calculation using Fick's law shows that the elapsed time between the end of irradiation and the beginning of mass spectrometry gas analysis is always much longer than the maximum time necessary for hydrogen to diffuse out of the samples. Then, it can be assumed that there is no residual hydrogen trapped in the material.

Gas analyses were performed using a quantitative gas mass spectrometer Thermo Fischer Scientific MAT-271 [6]. The instantaneous gas emission rate $\frac{1}{d} \cdot \frac{d\left[\mathrm{H}_{2}\right]}{d t}$, in $\mathrm{mol} \cdot \mathrm{J}^{-1}$, is obtained using equation (1):

$$
\frac{1}{d} \cdot \frac{d\left[H_{2}\right]}{d t}=\frac{P_{f} \cdot \%_{v o l} \cdot V_{\text {free }}}{R \cdot T \cdot D \cdot m}
$$

$d$ is the dose rate in Gy• $\mathrm{s}^{-1},\left[\mathrm{H}_{2}\right]$ corresponds to the hydrogen concentration in mol $\mathrm{kg}^{-1}$ measured after irradiation at a given dose $D$ itself expressed in Gy, $P_{f}$ refers to the total pressure in the glass 
ampoule at the end of the irradiation in $\mathrm{Pa}, \%_{v o l}$ is the gas volume fraction determined by gas mass spectrometry, $V_{\text {free }}$ denotes the free volume in the glass ampoule in $\mathrm{m}^{3}, R$ is the gas constant $\left(R \approx 8.314 \mathrm{~J} \cdot \mathrm{mol}^{-1} \cdot \mathrm{K}^{-1}\right), T$ defines the sample's temperature under irradiation in $\mathrm{K}$, and $m$ is the mass of the irradiated sample in $\mathrm{kg}$. The same equation is used for the determination of carbon monoxide radiation chemical yields.

As irradiation of each sample was in most cases doubled, given gas instantaneous emission rates were calculated as the average of the two measurements, using equation (1). Standard deviation was determined. It was always lower than $10 \%$ for hydrogen release and in most cases higher for carbon monoxide. Whatever the irradiation employed at room temperature, radiation chemical yields given are always mean values obtained using two experimental points. For some few points under $\gamma$-rays at temperatures higher than ambient one, only one glass ampoule could be irradiated

213 (for all numerical values, see Table S3 of the Supplementary Information). In such case, errors 214 bars given are the mean error bars (in percentage) of the other experimental data: it accounts for $6 \%$ for hydrogen release, and $17 \%$ for carbon monoxide.

\section{Pristine materials characterization}

218 To understand precisely mechanisms that are underlying the radiation protection effect towards 219 unsaturated bonds in non-perfect polyethylenes, nature, position and concentration of the 220 defects have to be known. Precise characterization of pristine polymers is thus necessary.

221 Infrared analyses were performed to confirm the presence and the nature of the chemical 222 defects of polyethylenes. Thermal analyses were used to evaluate the thermal properties and the 223 crystallinity of the polymers. Crystallinity has been shown to present no direct influence on the 224 hydrogen radiation-chemical yields when saturated aliphatic polymers are irradiated at room 225 temperature [6] that is why they are presented in the Supplementary Information. Nevertheless, 226 this parameter gives an idea of the samples' structural order. Moreover, as the physical state of 227 the polymers is a key parameter, especially for irradiations performed at high temperatures, 228 melting temperatures of the materials were determined.

229 In the case where materials are less well defined, complementary characterizations have been 230 performed. It applies to polyethylenes containing $\mathrm{C}=\mathrm{O}$ defects, supposed to be neat ones when 231 purchased. 


\subsection{Perfect polyethylenes}

234 The melting temperatures of the perfect polyethylenes are $132{ }^{\circ} \mathrm{C}$ for PE $181900,133^{\circ} \mathrm{C}$ for PE 235 GURa and $134^{\circ} \mathrm{C}$ for PE Goodfellow, respectively.

236

237

238

239

240

241

242

Figure 1 shows the infrared spectra, in the ATR mode, of the perfect polyethylenes under study. PE GURa and PE Goodfellow present infrared spectra equivalent to the one of pure polyethylene $[23,24]$. Nevertheless, in the case of PE 181900 purchased from Sigma-Aldrich, two very weak bands, centered at $990 \mathrm{~cm}^{-1}$ and at $909 \mathrm{~cm}^{-1}$ can be observed. They are characteristic of vinyl $\mathrm{CH}$ wagging and $\mathrm{CH}_{2}$ wagging modes, respectively [25]. Due to their weak intensity, this polymer was classified into the category of the perfect materials.
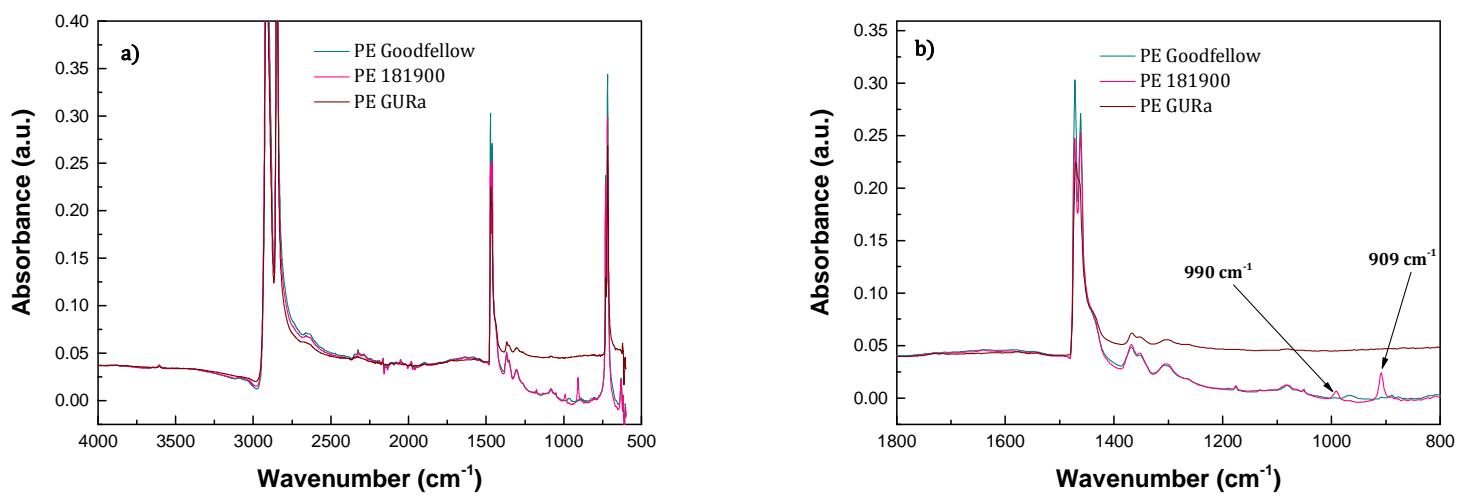

Figure 1. FTIR-ATR spectra of the perfect polyethylenes under study. a) Infrared spectra in the range $4000-600 \mathrm{~cm}^{-1}$. b) Zoom in the $1800-800 \mathrm{~cm}^{-1}$ area.

\subsection{Polyethylenes containing $\mathrm{C}=\mathrm{C}$ defects}

Two polymers containing $\mathrm{C}=\mathrm{C}$ double bonds were studied in this work. MB150 is a random ethylene/butadiene copolymer, composed of $95 \%$ of ethylene and of $5 \%$ of butadiene. It can thus be deduced that the vinylenes bonds are located on the backbone of the polymer. On the contrary, EPDMh is a terpolymer containing $75 \%$ of ethylene, $19 \%$ of propylene and $6 \%$ of 1,4hexadiene [21]. In this case, the vinylenes bonds are located on the polymer side-chain.

The melting temperatures of these methylene based polymers are $118{ }^{\circ} \mathrm{C}$ for MB150 and $48{ }^{\circ} \mathrm{C}$ for EPDMh, respectively.

ATR-FTIR spectra of the polyethylenes containing $\mathrm{C}=\mathrm{C}$ double bonds, are compiled in Figure 2 . The signature of trans-vinylene wagging vibration, at $965 \mathrm{~cm}^{-1}$, can easily be identified. In case of EPDMh, the intense band at $1376 \mathrm{~cm}^{-1}$ corresponds to the methylene bending mode of the propylene repetition units [25]. 

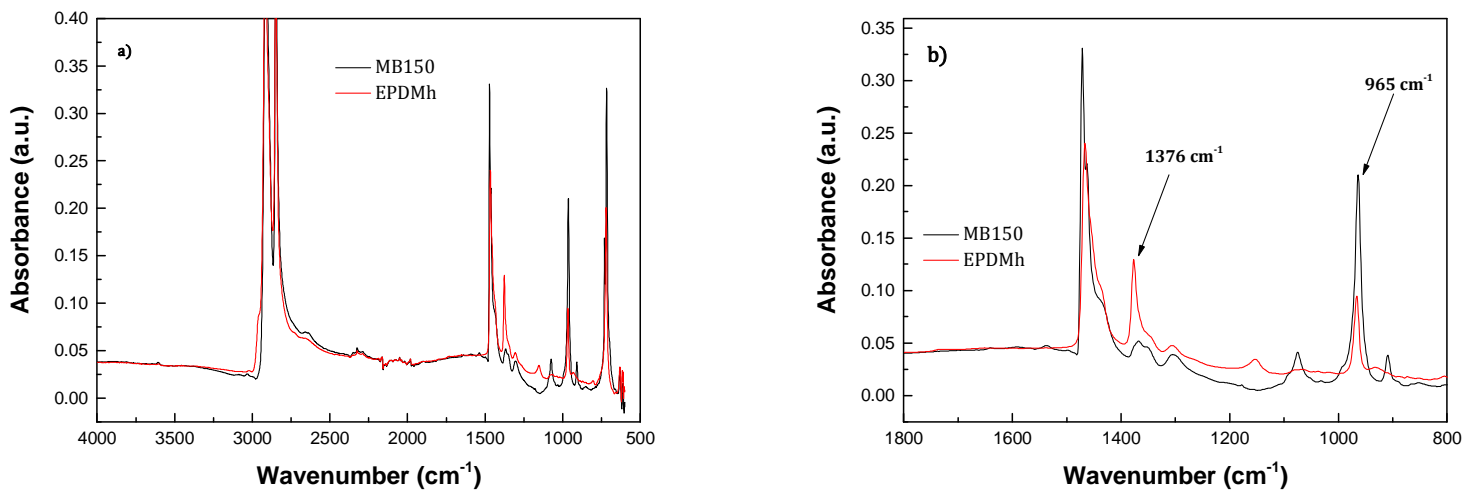

258

\section{2}

263

264

265

266

267

268

269

270

271

Figure 2. FTIR-ATR spectra of the polyethylenes containing $\mathrm{C}=\mathrm{C}$ bonds. a) Infrared spectra in the range $4000-600 \mathrm{~cm}^{-1}$. b) Zoom in the $1800-800 \mathrm{~cm}^{-1}$ area.

\subsection{Polyethylenes containing $\mathrm{C}=0$ defects}

As introduced in section 2.1, an important quantity of carbonyl bonds was evidenced in two polyethylenes.

The melting temperatures of $115^{\circ} \mathrm{C}$ was found for PE 427780 and of $107^{\circ} \mathrm{C}$ for PE 427772 , respectively.

The infrared spectra in the ATR mode are depicted in Figure 3. As indicated just above, the characteristic ketone stretching vibration, at $1720 \mathrm{~cm}^{-1}$, can easily be identified in both polymers [25]. The relative absorbance of this band is two times greater in PE 427772 than in PE 427780. As the intensity of the $-\mathrm{CH}_{2}$ - repetition units are equivalent in both spectra, it can be deduced that the concentration of $\mathrm{C}=0$ bands is two times larger in PE 427772 than in PE 427780.
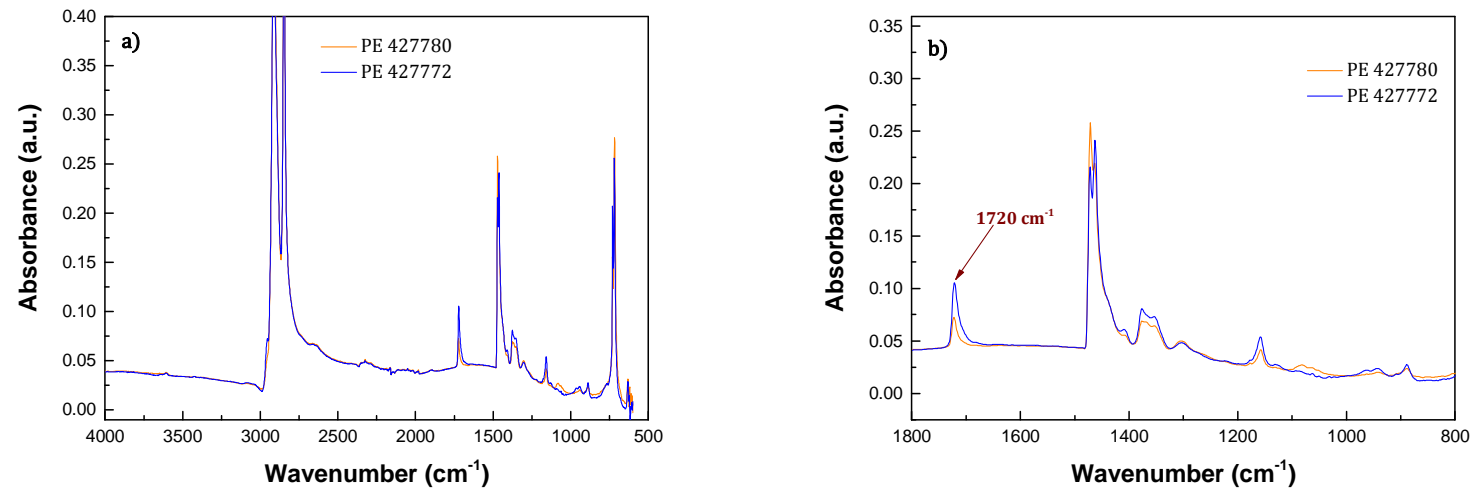

Figure 3. FTIR-ATR spectra of the polyethylenes containing $\mathrm{C}=0$ bonds. a) Infrared spectra in the range $4000-600 \mathrm{~cm}^{-1}$. b) Zoom in the $1800-800 \mathrm{~cm}^{-1}$ area. 
276 In order to obtain more detailed information about polymer chemical compositions, i.e. to 277 identify the position of these ketone bonds (in-chain defect and/or impurity), additional 278 characterizations by ${ }^{1} \mathrm{H}$ NMR, ${ }^{13} \mathrm{C}$ NMR and Py-GC-MS have been performed. They are presented 279 in Supplementary Information, because they do not allow to distinguish the presence and/or the 280 position of $\mathrm{C}=\mathrm{O}$ bonds, maybe because of the detection limits of these analytical methods. It can 281 nevertheless be concluded from these techniques that the two polyethylenes under study are 282 branched ones. To discriminate if the carbonyl bonds are present on impurities or on the 283 polymer backbone, extraction/precipitation of the materials was realized. About $0.1 \mathrm{~g}$ was 284 solubilized at $100{ }^{\circ} \mathrm{C}$ in $3 \mathrm{~mL}$ of toluene; once solubilized, $3 \mathrm{~mL}$ of dichloromethane was added to 285 allow precipitation. To separate solubilized and precipitated fractions, centrifugation was 286 realized (13 $400 \mathrm{rpm}$ for $5 \mathrm{~min}$ ). Solid fraction was weighted before and after this manipulation, 287 and at least $90 \%$ of the material remains solid, meaning that soluble impurities represent only a 288 weak part of the material. The liquid fraction was analyzed by GC-MS. Even non quantitative, it 289 can be remarked that the number of identified impurities is always smaller in PE 427780 than in 290 PE 427772. Obtained chromatograms and identified chemical compounds are gathered in 291 Supplementary Information.

292 Potassium bromide pellets containing the different fractions of polymer were prepared and 293 analyzed in transmission mode using FTIR spectroscopy. Spectra of PE 427772 are given on 294 Figure 4. It can be observed that the ketone stretching vibration, at $1720 \mathrm{~cm}^{-1}$, is present in the 295 extract and in the precipitate. 


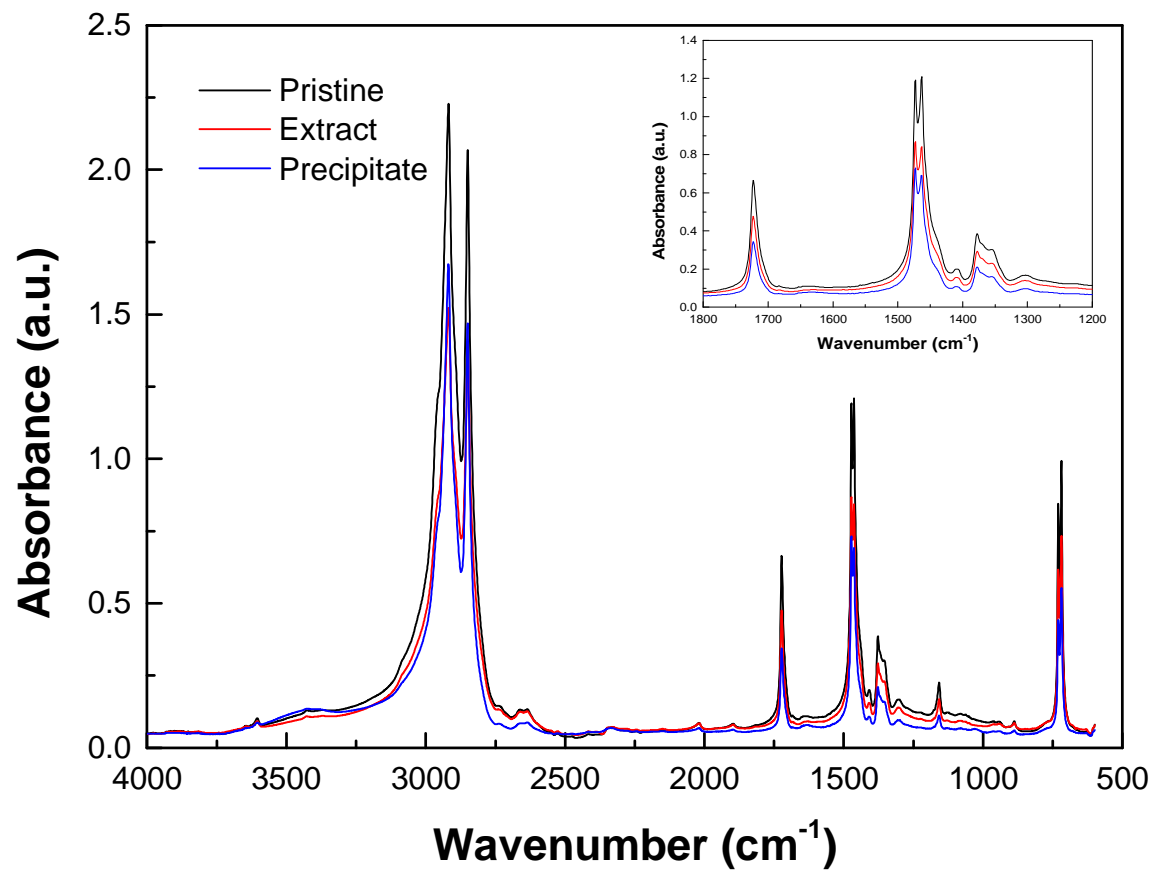

Figure 4. FTIR spectra of the PE 427772 (pristine, soluble part, precipitate). Insert: zoom on the $1800-1200 \mathrm{~cm}^{-1}$ area.

300

301

302

303

304

305

306

307

308

309

310

311

312 (numerical data are given in Table S3 of the Supplementary Information). The results obtained 313 by Chang and LaVerne [4] on their polyethylenes was also included as a "line to guide the eye".

From the extraction/precipitation and the FTIR experiments, it can be concluded that ketone bonds are present in the backbone and impurities. Nevertheless, as these impurities represent less than $10 \%$ of the materials, we will consider in the following that $\mathrm{C}=0$ ketone bonds are defects in the backbone and neglect the small proportion present in the impurities. Using infrared spectroscopy in transmission mode and the Beer-Lambert law, we could estimate that $[\mathrm{C}=0]_{\mathrm{PE}} 427772 \approx 0.6 \mathrm{~mol} \cdot \mathrm{kg}^{-1}$ (i.e. about $1.7 \%_{\mathrm{wt}}$ ) and $[\mathrm{C}=0]_{\mathrm{PE} 427780} \approx 0.3 \mathrm{~mol} \cdot \mathrm{kg}^{-1}$ (i.e. about $0.8 \%{ }_{\mathrm{wt}}$ ).

Both PE 427772 and PE 427780 are branched polyethylenes with ketone bonds, containing a small quantity of impurities, also containing ketone bonds.

\section{Results and discussion}

\subsection{LET effect}

Figure 5 shows the hydrogen radiation chemical yields obtained with the different polymers 


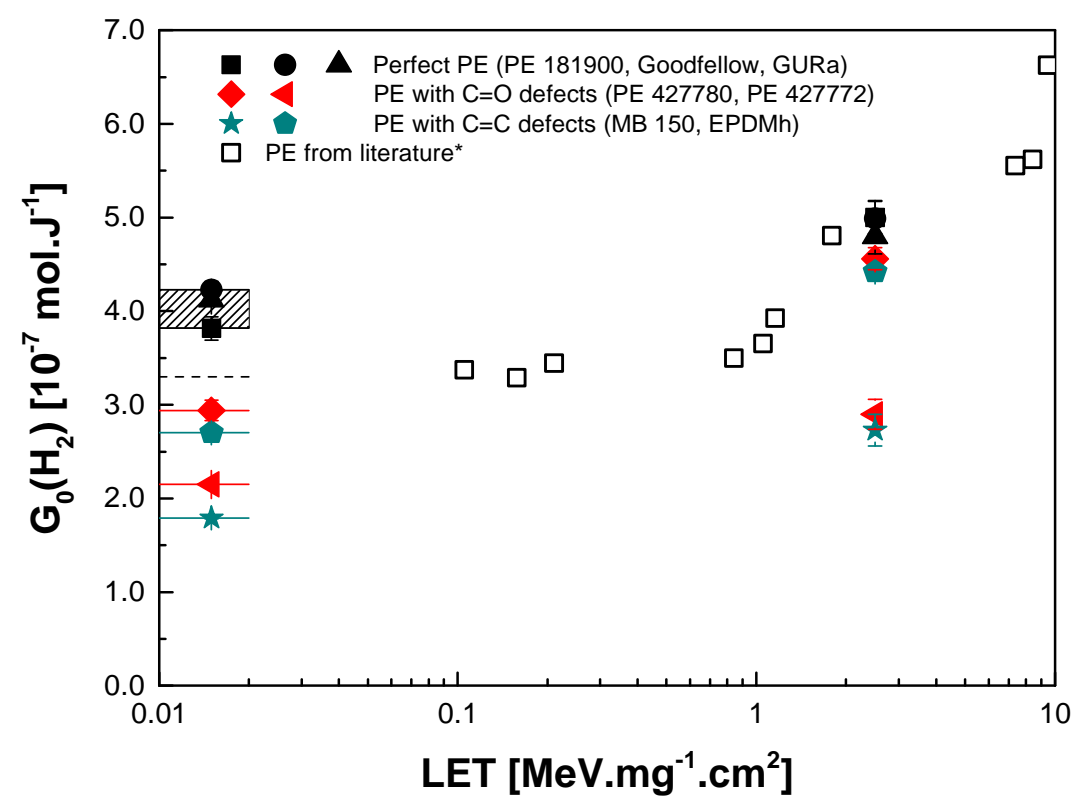

314

Figure 5. Hydrogen radiation chemical yields as a function of LET for different polyethylenes irradiated under helium atmosphere. Dash line and open squares: results from Chang and LaVerne [4].

319 It should be emphasized from Figure 5 that polyethylenes Goodfellow and GURa present 320 equivalent hydrogen radiation chemical yields using $\gamma$-rays, but $G_{0}\left(\mathrm{H}_{2}\right)$ evolved from PE 181900 321 is lower. It can probably be attributed to the vinyls bonds protection effect $[10,17]$, the presence 322 of these double bonds having been evidenced using FTIR spectroscopy (see section 3.1). By 323 using Swift Heavy Ions irradiation (SHI), it is observed that the three neat polyethylenes have equivalent $G_{0}\left(\mathrm{H}_{2}\right)$. It can be deduced from this observation that at higher LET, the hydrogen radiation chemical yields of the three neat polyethylenes are equivalent, so vinyl bonds are no more effective to protect PE. This might at least partially be explained by two facts. The first one is that vinyl bonds are defects that are present only as side-chain effect, and not in the polymeric backbone. In our previous work focused on the effect of ester bonds position effect in methylene containing polymers, we have observed that in-chain defects are substantially more efficient that defects position on side-chains [6]. The second hypothesis comes from the fact that the radiation protection effects of protective bonds are diminished when LET is increasing [3, 4, 26]. It might

332 be concluded that even at low LET, vinyl bonds are less effective than in-chain double bonds to 333 protect polyethylene. Moreover, it seems that the protection effect conferred by these double 334 bonds is lost at lower LET than the one conferred by trans-vinylene bonds. 
Figure 5 shows also that at low as at high LET, whatever the kind of double bond $(\mathrm{C}=0$ and $\mathrm{C}=\mathrm{C}$ ), the hydrogen radiation yield is decreased when compared with the neat polyethylenes. These two kinds of bonds are known to be effective scavenging groups $[9,10]$ under low LET irradiation. Here we show that energy transfers towards these defects are efficient whatever the nature of irradiation.

The difference between the two materials containing $\mathrm{C}=\mathrm{C}$ bonds is the position of the defect in the polymer. The concentration of unsaturations is relatively equivalent in both materials. MB150 presents 5\% of unsaturations in the backbone to be compared to $6 \%$ in EPDMh [21] on side-chains. The difference in $G_{0}\left(H_{2}\right)$ is in agreement with our precedent work [6] and with the Partridge's model [18] for energy transfers on polyethylene irradiated using $\gamma$-rays. Partridge estimated that about $1 / 3$ of the excitations are localized on $\mathrm{C}-\mathrm{H}$ bonds and cannot migrate, whereas $2 / 3$ are localized on $\mathrm{C}-\mathrm{C}$ bonds and are allowed to move along the repetition units. In this work, $\mathrm{C}-\mathrm{H}$ bonds are equivalent to side-chain and $\mathrm{C}-\mathrm{C}$ bonds correspond obviously to the backbone. By roughly estimating from pure polyethylene the decrease, under $\gamma$-rays, due to a scavenger respectively in-chain and side-chain, we obtain:

350

- In-chain hydrogen radiation chemical yield (decrease of 2/3 of $G_{0}\left(H_{2}\right)_{P E \text { Goodfellow): }}$ $1.4 \cdot 10^{-7} \mathrm{~mol} \cdot \mathrm{J}^{-1}$ to be compared to $1.8 \cdot 10^{-7} \mathrm{~mol} \cdot \mathrm{J}^{-1}$ determined for MB150,

- Side-chain hydrogen radiation chemical yield (decrease of $1 / 3$ of $G_{0}\left(H_{2}\right)_{P E \text { Goodfellow): }}$ $2.8 \cdot 10^{-7} \mathrm{~mol} \cdot \mathrm{J}^{-1}$ to be compared to $2.7 \cdot 10^{-7} \mathrm{~mol} \cdot \mathrm{J}^{-1}$ determined for EPDMh.

The position and the concentration of the defects have an influence on the radiation chemical yields, which is in agreement with the Partridge's model.

For both MB150 and EPDMh irradiated using SHI, the radiation protection effect conferred by the $\mathrm{C}=\mathrm{C}$ double bond is decreased compared to irradiations using $\gamma$-rays. However, the evolution is not equivalent for both materials, i.e. for both defects position. The radiation protection effect is almost lost in case of EPDMh. On the contrary, when defects are in the backbone, radiation protection effect, although less effective than under low LET irradiations, remains active. Regardless of the position of the energy sink, it has been shown by Chang and LaVerne [4] and by Ferry et al. [26] that increasing LET induces a loss of radiation protection efficiency, which implies a loss of energy and radical migration. As on side-chains, energy transfers are already drastically reduced compared to in-chains migration under low LET ionizing rays, it can probably be supposed that their protection efficiency will be lost at a LET lower than the one needed to lose the protection induced from in-chains defects. This is exactly what is observed under our SHI irradiations conditions: $G_{0}\left(H_{2}\right)_{E P D M h} \approx G_{0}\left(H_{2}\right)_{P E \text { Goodfellow }}$ whereas 
migration are highly efficient in the case of unsaturations on the backbone. It is therefore very

370 probable that under our conditions, only part of the efficiency is lost. It could have been

371 interesting to validate this hypothesis by irradiating MB150 at LET higher than the one of this

372 study.

373 Polyethylenes containing $\mathrm{C}=0$ defects are of great interest because their defects are positioned

374 equivalently but their concentration is different: PE 427772 has about twice more $\mathrm{C}=0$ defects

375 than PE 427780, numerical values of their concentration being approximations (see section 3.3).

376 Figure 6 presents, as a function of the $\mathrm{C}=0$ content, the results obtained for one neat

377 polyethylene (PE Goodfellow has been chosen) without any ketone bond in its structure before

378 irradiation, and the two PE with ketones moieties.

379 From Figure 6, it can be observed for hydrogen release evolution that slopes of the two linear

380 regressions are almost equivalent in the ketone concentration range of this study. The difference

381 observed between $\gamma$-rays and SHI irradiations is only due to the difference of energy deposition

382 between the two kinds of irradiations, but the ketone bonds are efficient scavengers in both 383 cases, and in an equivalent proportion.

384 Figure 6 shows also that contrary to the hydrogen evolution, the one of the carbon monoxide 385 release is very dependent on the irradiation nature. Its linear regressions slope is five times 386 more important under $\gamma$-rays than under SHI irradiations. This implies that the mechanisms 387 which lead to the formation of these two gases are completely different. The one leading to CO is 388 highly energy and radical transfers dependent. The generally admitted mechanism for CO comes 389 from the decomposition of the ketone bonds by the Norrish type I mechanism [27, 28], 390 presented in Scheme 1. This seems to imply that Norrish type I reaction is influenced by these 391 kind of migration. 


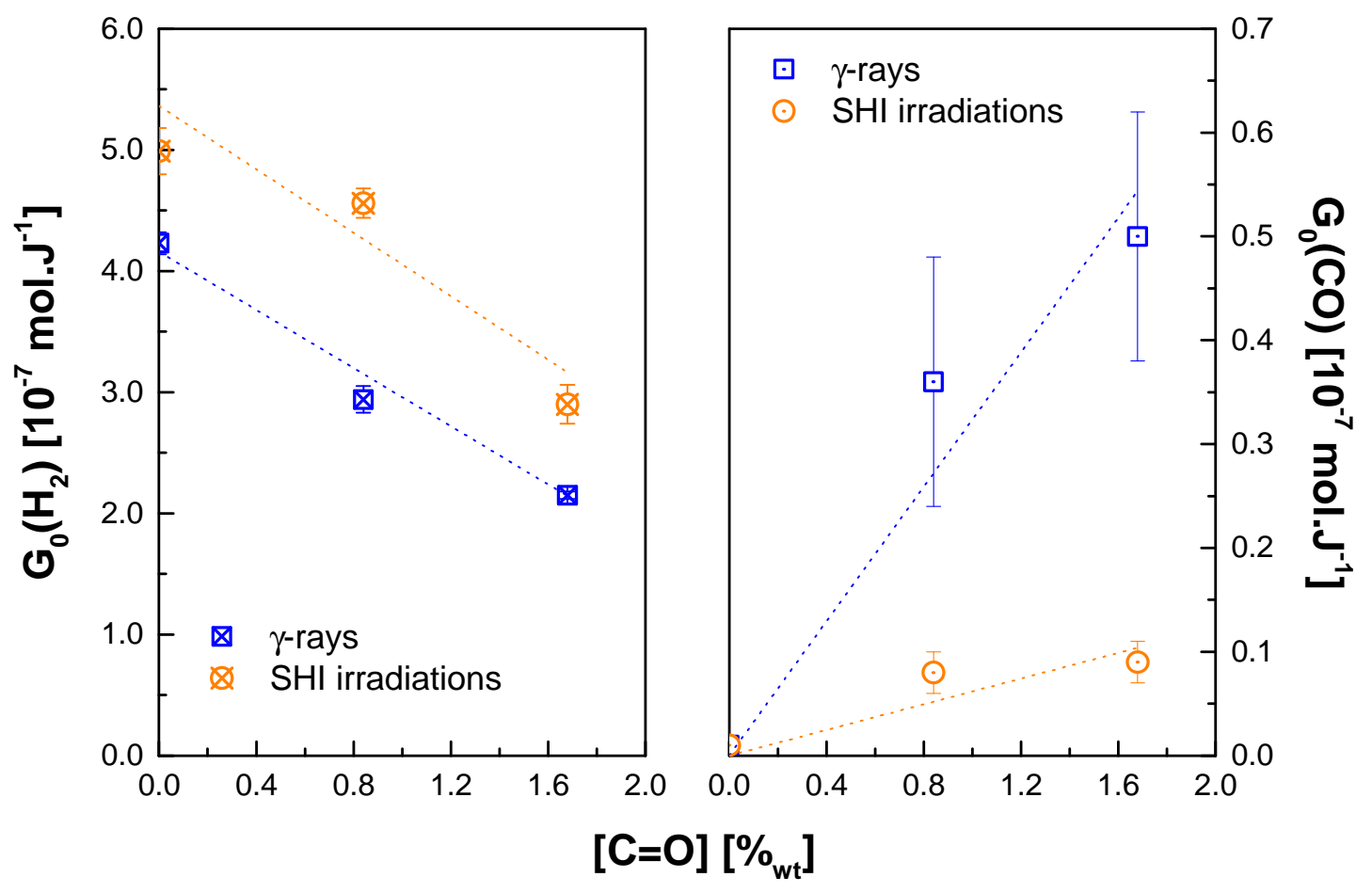

Figure 6. Radiation chemical yields as a function of the initial carbonyl concentration in PE containing $\mathrm{C}=\mathrm{O}$ bonds. On the left, hydrogen release and on the right, carbon monoxide release. Dot lines: linear regressions.

396

397

398

399

400

401

402

403<smiles>CCCC(=O)CCC</smiles>

hv<smiles>C=CCCC</smiles><smiles>CCC</smiles><smiles>[Y][As]=[Se][SeH]</smiles><smiles>CC[C+]=O</smiles>

Scheme 1. Formation of carbon monoxide via Norrish I mechanism.

\subsection{Temperature effect}

Radiation chemical yields for hydrogen and carbon monoxide evolved from polyethylenes irradiated at various temperatures by $\gamma$-rays are compiled in Figure 7 (numerical data are given in Table S4 of the Supplementary Information). Dashed lines are added to guide the eye. 
To the best of our knowledge, such level off of $\mathrm{G}_{0}\left(\mathrm{H}_{2}\right)$ with increasing irradiation temperature has not been described in the literature [12-16]. The authors report the hydrogen emission increasing with temperature ranging from room one to $300^{\circ} \mathrm{C}$, however with different kinetics.

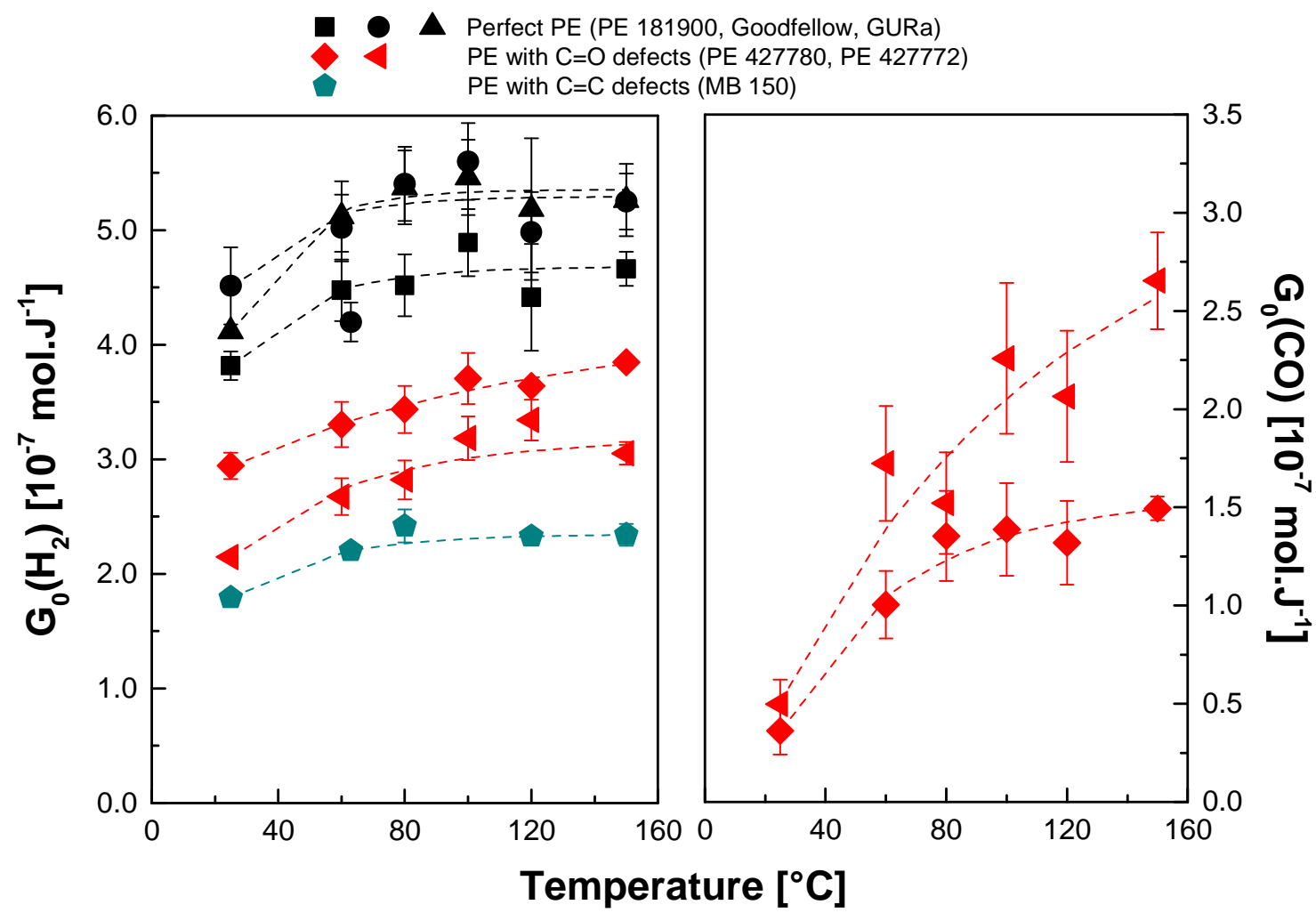

Figure 7. Hydrogen (on the left) and carbon monoxide (on the right) radiation chemical yields as a function of irradiation temperature for different polyethylenes irradiated under helium atmosphere. Dashed lines are added to guide the eye.

As seen in Figure 7, perfect polyethylenes form the highest amount of $\mathrm{H}_{2}$ by the deposited energy among all tested materials. The distinction in $\mathrm{H}_{2}$ formation between polyethylenes of different initial composition can be explained by two phenomena. Either the radiation protection effect of double bonds (carbonyl or vinyl) present in polymers is increasing with temperature, or the differences in the degree of crystallinity of the materials can begin to play a role.

417 Nevertheless, as often stated in the literature $[6,20,29]$, we believe that the crystallinity will not play a major role, especially above the melting temperature. Hence, we suppose that the radiation protection effect of the two kinds of double bonds under study is at least thermally activated. We note also that the $\mathrm{G}_{0}\left(\mathrm{H}_{2}\right)$ value levels off at about $80{ }^{\circ} \mathrm{C}$ for all tested materials with the exception of PE 427772 for which it starts to stabilize at around $120{ }^{\circ} \mathrm{C}$. This difference in temperature stabilization demonstrates thus different kinetics of hydrogen formation. 
423 One of the perfect polyethylenes, namely PE 181900, is characterized by lower values of $\mathrm{G}_{0}\left(\mathrm{H}_{2}\right)$

424 in the analyzed range of irradiation temperatures than other ones. As already mentioned in the

425 preceding section, this fact can be explained by the presence of a very low content of effective

426 scavenging vinyls bonds in the chemical structure of this polymer.

427 Among the materials with confirmed presence of carbonyl defects, PE 427772 is characterized

428 by a lower hydrogen radiation chemical yield than PE 427780, which has previously been

429 explained by its higher ketone bonds concentration. The $\mathrm{C}=0$ groups present in polymer

430 backbone become the site of a hydrogen atom abstraction process, leading to the formation of

431 secondary alcohols. This mechanism contributes to the hydrogen radiation chemical yields

432 decrease. This is consistent with the work of Slivinskas et al. [9], who studied the effect of ketone

433 polymers on radiation chemical yields and explained the $\mathrm{H}_{2}$ emission quenching by the

434 intermolecular energy transfer to the carbonyl group along the polymer chain. This mechanism

435 implies the intramolecular charge transfer between neighboring molecules (see Scheme 2

436 below). In turn, PE 427780 presents a behavior closer to a perfect material, as it contains lower

437 amount of scavenging $\mathrm{C}=0$ groups.

438 The protective role of $\mathrm{C}=\mathrm{C}$ bonds on the MB150 backbone is also evidenced from Figure 7 [10].

439 The radiation chemical yields for hydrogen production determined for this material is the lowest

440 one among all the polymers containing double bonds defects in their structure. This observation

441 can come from the difference in their concentration or in a difference in the kind of double

442 bonds efficiency. To differentiate these two hypotheses, the evolution of the relative radiation

443 chemical yields of molecular hydrogen emission at room temperature $\frac{G_{0}\left(H_{2}\right)_{P E \text { with defects }}}{G_{0}\left(H_{2}\right)_{\text {Perfect PE }}}$ as a

444 function of the concentration of chemical defects present in analyzed polyethylenes is depicted

445 in Figure 8, along with the results of Slivinskas et al. [9] (ketone groups) and of Ventura et al.

$446[10]$ (trans-vinylene groups). The results obtained in this work are in good agreement with those

447 from the literature and confirm that the main influence on hydrogen radiation chemical yield is

448 coming from the concentration of chemical defects, not from their nature.

449 In Figure 8, the superposition of the curves relative to ketones and trans-vinylenes suggests that

450 the mechanism of quenching is the same for both types of defects. It is supposed that part of the

451 energy deposited migrates and is transferred to $\mathrm{C}=\mathrm{O}$ or $\mathrm{C}=\mathrm{C}$ groups. Data presented in Figure 8

452 show that a small concentration of defects reduce significantly hydrogen radiation chemical

453 yields. This result can only be explained by assuming that the excitation can be transferred over

454 large distances, which is reminiscent with the Partridge model [18]. Recent ab initio simulations

455 carried out by Ceresoli et al. [30] confirmed the rapid migration of exciton along the chain and 456 its trapping by trans-vinylene and carbonyl defects. In the same way, Ventura et al. [10] 
supposed that the energy transfer is possible only in a "sphere of action" around each defects.

458 Then, if the excited molecule is within this sphere, it is fully or partly deactivated. The expression 459 of the relative hydrogen yield is given by equation (2):

$$
\frac{G_{0}\left(H_{2}\right)_{C}}{G_{0}\left(H_{2}\right)_{\text {Perfect } P E}}=\alpha^{n s}+\left(1-\alpha^{n s}\right) \cdot e^{-v \cdot N_{A} \cdot C \cdot \rho}
$$

460

461

462

463

464

$\alpha^{n s}$ denotes the non-scavengeable energy fraction, $v$ corresponds to the "sphere of action" volume in $\mathrm{m}^{3}, N_{A}$ is the Avogadro number in $\mathrm{mol}^{-1}, C$ refers the defects concentration in mol $\mathrm{kg}^{-1}$ and $\rho$ is the density in $\mathrm{kg} \cdot \mathrm{mol}^{-1}$. For both defects (ketones and trans-vinylenes), $\alpha^{n s}$ is comprised between 0.40 and 0.45 . This parameter represents either the protection efficiency of the defects or the processes that cannot be scavenged by the defects (non-scavengeable energy).

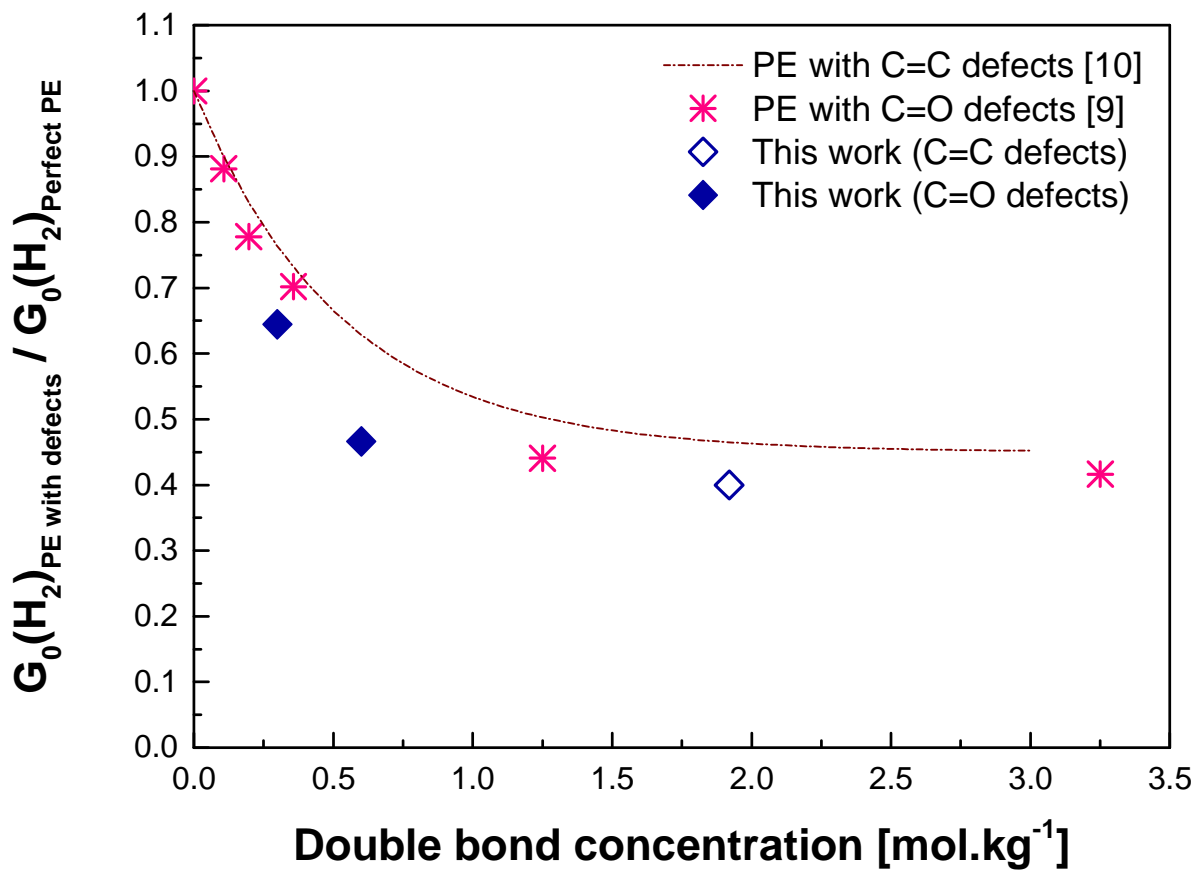

465

466

467

468

469

470

471

472

473 474
Figure 8: Evolution of relative hydrogen radiation chemical yield of molecular hydrogen emission at room temperature as a function of the concentration of chemical defects (ketones or transvinylenes). Results obtained in this work and from the literature [9, 10].

If we consider the temperature effect on hydrogen release presented in Figure 7, then the radiation chemical yields for analyzed perfect polyethylenes increase when the irradiation temperature exceeds the ambient one. At around $100{ }^{\circ} \mathrm{C}$, it starts to stabilize, when taking into account the measurements errors. Very similar dependence is observed for materials containing $\mathrm{C}=\mathrm{O}$ or $\mathrm{C}=\mathrm{C}$ defects. 
As shown in Figure 8, if the concentration of defects $C$ exceeds $1.5-2.0 \mathrm{~mol} \cdot \mathrm{kg}^{-1}$ then $\frac{G_{0}\left(H_{2}\right)_{C}}{G_{0}\left(H_{2}\right)_{\text {Perfect } P E}} \approx \alpha^{n s}$. In other words, hydrogen release at room temperature results solely from non-scavengeable energy. If this estimation is used on hydrogen radiation chemical yields obtained for MB150 with the $G_{0}\left(H_{2}\right)_{P e r f e c t ~}^{P E}\left(25^{\circ} \mathrm{C}\right)$ used as the reference value, then the following fractions, which are represented in Figure 9, can be calculated:

$$
\alpha^{n s}(T) \approx \frac{G_{0}\left(H_{2}\right)_{M B 150}(T)}{G_{0}\left(H_{2}\right)_{P \operatorname{Perfect} P E}\left(25^{\circ} \mathrm{C}\right)} \quad \text { and } \quad \alpha^{S}(T) \approx \frac{G_{0}\left(H_{2}\right)_{P \operatorname{erfect} P E}(T)-G_{0}\left(H_{2}\right)_{M B 150}(T)}{G_{0}\left(H_{2}\right)_{P \operatorname{erfect} P E}\left(25^{\circ} \mathrm{C}\right)}
$$

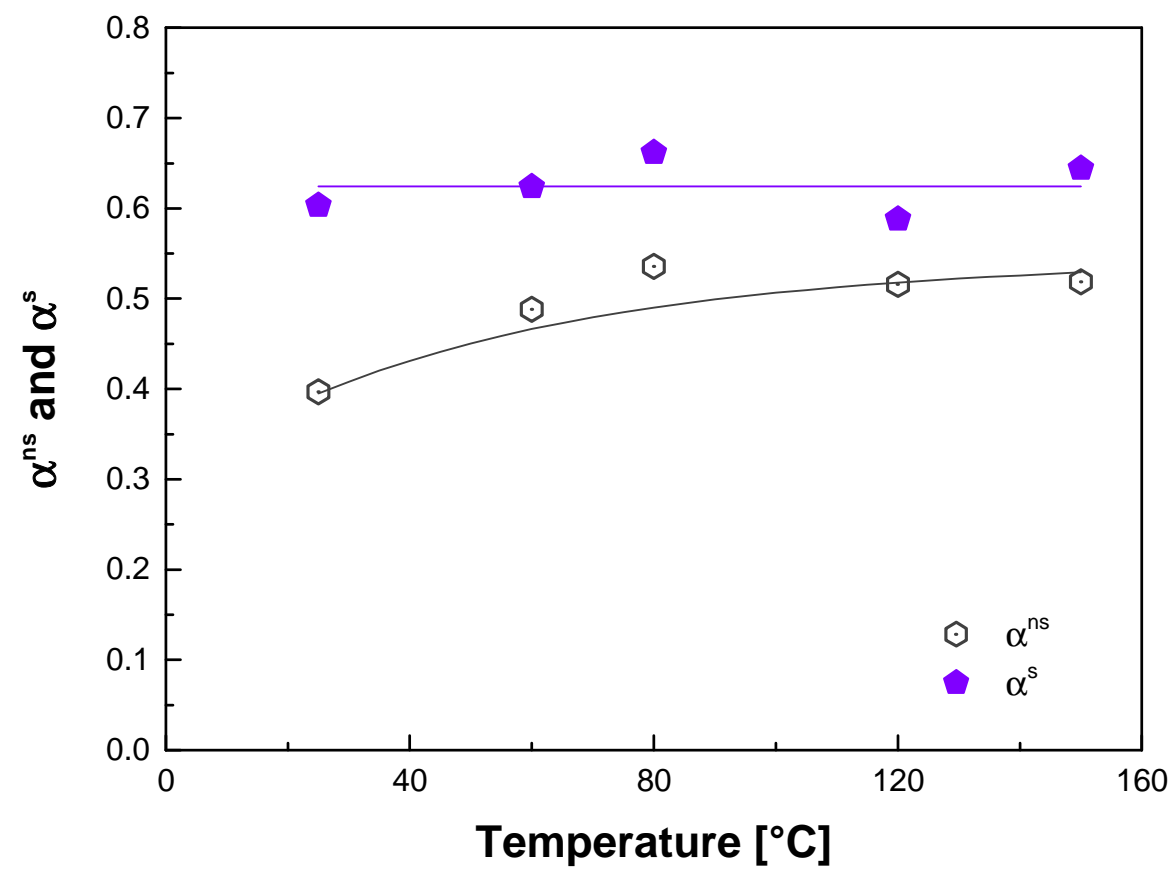

481

Figure 9: Temperature dependence of the non-scavengeable energy fraction $\left(\alpha^{n s}\right)$ and of the scavengeable energy fraction $\left(\alpha^{s}\right)$. Results obtained on $\mathrm{G}_{0}\left(\mathrm{H}_{2}\right)$ for MB150.

It is evidenced that $\alpha^{s}$, which designs the scavengeable energy fraction, is roughly constant whatever the irradiation temperature and that the temperature favors the non-scavengeable process. Finally, performed experiments suggest that hydrogen results from at least two distinct mechanisms with different thermal dependence: i) athermal for the scavengeable energy fraction and ii) temperature-dependent for the non-scavengeable energy fraction.

One possible explanation of the $\alpha^{n s}$ apparent increase with the temperature rise is the reduction of the protection efficiency of defects. Nevertheless, this interpretation can be discarded because it is not relevant for polyethylene without defects. The explanation has to be found in primary 
500

501

502

503

504

505

506

507

508

509

510

511

512

513

514

515

516

517

518

519

520

mechanism of hydrogen formation. By analogy with alkane radiolysis, hydrogen formation in polyethylene is supposed to result from the decay of excited states and involves the two following mechanisms [31-33]:

- $\quad S_{1} \rightarrow S_{X}$-type internal conversion transitions (IC) that are mainly temperature dependent and lead to $\mathrm{H}_{2}$ elimination:

$$
-\mathrm{CH}_{2}-\mathrm{CH}_{2}^{*}-\rightarrow-\mathrm{CH}=\mathrm{CH}-+\mathrm{H}_{2}
$$

- $S_{1} \rightarrow T_{n}$-type intersystem crossing processes (ISC) that are mainly temperature independent and in which triplet state decomposes into radical intermediate products:

$$
\begin{gathered}
-\mathrm{CH}_{2}-\mathrm{CH}_{2}^{*}-\rightarrow-\mathrm{CH}_{2}-\mathrm{CH}^{\circ}-+\mathrm{H}^{\circ} \\
-\mathrm{CH}_{2}-\mathrm{CH}_{2}-+\mathrm{H}^{\circ} \rightarrow-\mathrm{CH}_{2}-\mathrm{CH}^{\circ}-+\mathrm{H}_{2}
\end{gathered}
$$

The temperature dependence of hydrogen yield is assumed to be due to IC transitions. This interpretation suggests also that the non-scavengeable energy is related to $\mathrm{H}_{2}$ elimination rather than $\mathrm{H}$ atom elimination. According to Partridge [18], this conclusion is problematic as the nonscavengeable energy represents the non-migratory ( $\mathrm{C}-\mathrm{H}$ bond) excitation which is believed to cause $\mathrm{C}-\mathrm{H}$ bond scission.

Apart from the formation of hydrogen, the emission of carbon monoxide from polyethylenes containing initially carbonyl groups in their polymer backbone is observed. As the $\mathrm{C}=0$ repetition units are the sole potential source of carbon monoxide, it can be deduced that carbon monoxide is evolved from the degradation of the polymer specifically localized at the ketone bonds.

Some theoretical ab initio simulations were carried out by Ceresoli et al. [30] in order to understand the evolution of an exciton trapped on trans-vinylene and carbonyl defects which are present in polyethylene. The authors report that excitons trapped by $\mathrm{C}=\mathrm{O}$ and $\mathrm{C}=\mathrm{C}$ bonds lead to weakening of these linkages, but without their breaking. However, the researchers do not go so far as to propose a mechanism of ketone cleavage according to the Norrish type I reaction (given on Scheme 1). This reaction involves both the singlet and triplet excited states of ketones and is strongly temperature dependent [34].

In Scheme 2, the excitation transfers and their de-excitation in $\mathrm{PE}$ containing $\mathrm{C}=\mathrm{O}$ is schematically given, along with the direct reaction of hydrogen formation. The two reactions with excitation migration which can be envisaged are thus chain scission and de-excitation without fragmentation. If Scheme 2 is believed to be true, hydrogen and carbon monoxide 
521 formations might be in competition: increase of one gas should imply the decrease of the other

522 one. It is obvious that this is not the case in this work (see Figure 7). It seems therefore that in 523 radiation- and temperature-induced modifications of polyethylenes next to scavenging ISC and 524 non-scavenging IC processes, the third one should probably be considered.
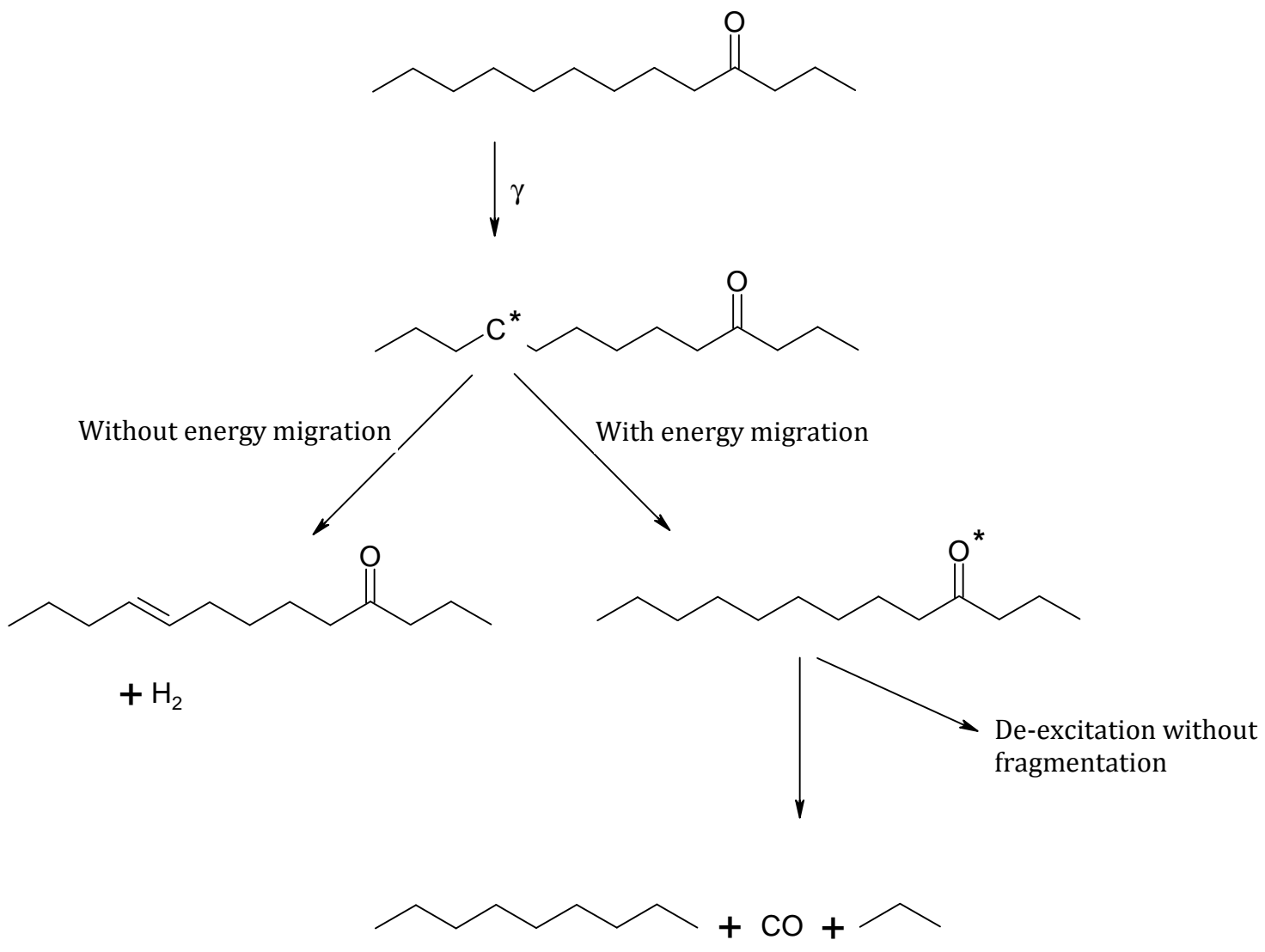


\section{Conclusions}

531 In order to assess the potential risks in safety management of nuclear packages containing 532 polymers, the potential accumulation of explosive gases during storage, transport and final 533 disposal has to be understood and well evaluated. We have investigated the two following 534 parameters:

535 - The Linear Energy Transfer (LET) effect by irradiating polymers using $\gamma$-rays and SHI,

536 - The irradiation temperature influence by irradiating polymers using $\gamma$-rays at 537 temperatures ranging from room temperature to $150{ }^{\circ} \mathrm{C}$.

538 We have studied various polyethylenes and methylene based polymers with specific defects 539 ( $\mathrm{C}=\mathrm{C}$ and $\mathrm{C}=\mathrm{O}$ groups), as these bonds are the main defects formed under irradiation 540 (depending on the atmosphere) and are effective energy and radicals scavengers.

541 By evaluating the LET effect, it has been shown that hydrogen radiation chemical yields is 542 increasing with the stopping power. It implies that the radiation protection of the defects under 543 study is less effective when LET increases. We have determined the effect of the trans-vinylene 544 bonds position (in-chain or on side-chain) at equivalent concentrations and we have observed 545 that the protection is more efficient if the $\mathrm{C}=\mathrm{C}$ group is located on the backbone. Concentration 546 effect of the double bonds has been determined on the polymers with ketone defects. For these 547 materials, hydrogen radiation chemical yield is decreasing in an equivalent proportion for $\gamma$-rays 548 and SHI irradiations: ketone bonds are efficient scavengers and in an equivalent proportion. On 549 the contrary, carbon monoxide released according to the Norrish type I mechanism, is highly 550 dependent on the nature of the irradiation, i.e. on the energy and radical transfers.

551 The efficiency of double bonds is dependent on their concentration in polymer matrix but not on

552 their nature (ketone or trans-vinylene bonds). The initial increase of $\mathrm{G}_{0}\left(\mathrm{H}_{2}\right)$ with the rise of 553 irradiation temperature was characteristic for all analyzed materials and resulted probably from 554 the growth of polymer chains vibration. By estimating the scavengeable and the non555 scavengeable energy fractions, it has been shown that hydrogen results from two distinct 556 mechanisms occurring with different thermal dependence, athermal and temperature557 dependent. For polyethylenes containing $\mathrm{C}=\mathrm{O}$ defects, a schematic reaction mechanism has been 558 proposed. In this process pathway, we suppose the existence of competitive reactions with and 559 without energy migration. Reactions with excitation migration are chain scission and de560 excitation without fragmentation.

561 Finally, it has been demonstrated that whatever the factors under study (LET and irradiation 562 temperature; defects concentration, position and nature), the hydrogen radiation chemical yield 
is decreased when $\mathrm{C}=\mathrm{C}$ or $\mathrm{C}=\mathrm{O}$ bonds are present in the materials. Obtained results are of great

564 significance because of nuclear safety purposes.

\section{Acknowledgement}

567 Authors would like to thank: F. Cochin and F. Nizeyimana (ORANO) for their fruitful discussions;

568 E. Oral (OBBL), M. Bousquié and C. Boisson (LCPP) for supplying samples; P. Le Tutour and P. 569 Quinot (CEA/LABRA) for the gamma irradiations; Y. Ngono-Ravache (CEA/CIMAP) for the ions 570 irradiations; S. Legand (CEA/LRMO) for her help during experiments. This work is financially 571 supported by ORANO and EDF.

\section{Bibliography}

574 [1] Chapiro A. Radiation chemistry of polymeric systems. London: Interscience Publishers; 1962.

575 [2] Dole M, Hedvig P, Humpherys KC, Keyser RM, Mandelkern L, Partridge RH, et al. The 576 radiation chemistry of macromolecules, volume I. London \& New York Academic Press Inc.; 5771972.

578 [3] Ferry M, Ngono-Ravache Y, Aymes-Chodur C, Clochard MC, Coqueret X, Cortella L, et al. 579 Ionizing Radiation Effects in Polymers. Reference Module in Materials Science and Materials 580

581

582

583

584

585 Engineering: Elsevier; 2016.

[4] Chang Z, LaVerne JA. Hydrogen Production in the Heavy Ion Radiolysis of Polymers. 1. Polyethylene, Polypropylene, Poly(methyl methacrylate), and Polystyrene. J Phys Chem B. 2000;104:10557-62.

[5] Alexander P, Charlesby A. Radiation protection in copolymers of isobutylene and styrene. Proceedings of the Royal Society of London Series A Mathematical and Physical Sciences. 1955;230:136-45.

[6] Ferry M, Dannoux-Papin A, Dély N, Legand S, Durand D, Roujou JL, et al. Chemical composition effects of methylene containing polymers on gas emission under $\gamma$-irradiation. Nucl Instrum Methods Phys Res, Sect B. 2014;334:69-76.

[7] LaVerne JA, Dowling-Medley J. Combinations of Aromatic and Aliphatic Radiolysis. The Journal of Physical Chemistry A. 2015;119:10125-9.

[8] Schoepfle CS, Fellows CH. Gaseous Products from Action of Cathode Rays on Hydrocarbons. Industrial \& Engineering Chemistry. 1931;23:1396-8.

[9] Slivinskas JA, Guillet JE. $\gamma$-radiolysis of ketone polymers. III. Copolymers of ethylene and carbon monoxide. Journal of Polymer Science: Polymer Chemistry Edition. 1974;12:1469-91.

[10] Ventura A, Ngono-Ravache Y, Marie H, Levavasseur-Marie D, Legay R, Dauvois V, et al. Hydrogen emission and macromolecular radiation-induced defects in polyethylene irradiated under an inert atmosphere: The role of energy transfers toward trans-vinylene unsaturations. J Phys Chem B. 2016;120:10367-80.

[11] Arai H, Nagai S, Matsuda K, Hatada M. Effect of irradiation temperature on the radiolysis of methane. Radiation Physics and Chemistry (1977). 1981;17:151-7.

[12] Wu G, Katsumura Y, Kudoh H, Morita Y, Seguchi T. Temperature dependence of radiation effects in polyethylene: Cross-linking and gas evolution. Journal of Polymer Science Part A: Polymer Chemistry. 1999;37:1541-8.

606 [13] Seguchi T, Haruyama Y, Sugimoto M. Temperature dependence of gas evolution from polyolefins on irradiation under vacuum. Radiation Physics and Chemistry. 2013;85:124-9. 
607 [14] Mitsui H, Shimizu Y. Kinetic study of the $\gamma$ radiolysis of polyethylene. Journal of Polymer 608 Science: Polymer Chemistry Edition. 1979;17:2805-13.

609 [15] Kang HY, Saito 0, Dole M. The Radiation Chemistry of Polyethylene. IX. Temperature 610 Coefficient of Cross-Linking and Other Effects. Journal of the American Chemical Society. 611 1967;89:1980-6.

612 [16] Bowmer TN, O'Donnell JH. Nature of the side chain branches in low density polyethylene: volatile products from gamma radiolysis. Polymer. 1977;18:1032-40.

[17] Seguchi T. Mechanisms and kinetics of hydrogen yield from polymers by irradiation. Nuclear Instruments and Methods in Physics Research Section B: Beam Interactions with Materials and Atoms. 2001;185:43.

[18] Partridge RH. Excitation Energy Transfer in Alkanes. I. Exciton Model J Chem Phys. 1970;52:2485.

[19] Alexander P, Charlesby A. Energy Transfer in Macromolecules Exposed to Ionizing Radiations. Nature. 1954;173:578.

621 [20] Williams TF, Dole M. Irradiation of Polyethylene. III. Influence of Temperature and Phase.

622

623

624

625

626

627

628

629

630

631

632

633

634

635

636

637 Journal of American Chemical Society. 1959;81:2919.

[21] Dély N. Radio-oxydation d'un élastomère de type EPDM lors d'irradiations faiblement ou fortement ionisantes : mesure et modélisation de la consommation de dioxygène. Caen: Université de Caen Basse Normandie; 2005.

[22] Ziegler JF. Particle Interactions with Matter. http://www.srim.org/.

[23] George GA, Celina M, Vassallo AM, Cole-Clarke PA. Real-time analysis of the thermal oxidation of polyolefins by FT-IR emission. Polymer Degradation and Stability. 1995;48:199210.

[24] Gulmine JV, Janissek PR, Heise HM, Akcelrud L. Polyethylene characterization by FTIR. Polymer Testing. 2002;21:557-63.

[25] Colthup NB, Daly LH, Wiberley SE. Introduction to Infrared and Raman Spectroscopy, 3rd ed. Boston: Academic Press, Inc./Harcourt Brace Jovanovich; 1990.

[26] Ferry M, Ngono-Ravache Y, Picq V, Balanzat E. Irradiation of Atactic Polystyrene: Linear Energy Transfer Effects. Journal of Physical Chemistry B. 2008;112:10879.

[27] Geuskens G. Chapter 3 Photodegradation of Polymers. In: Bamford CH, Tipper CFH, editors. Comprehensive Chemical Kinetics: Elsevier; 1975. p. 333-424.

638 [28] Rabek JF. Photodegradation of polymers: physical characteristics and applications. Berlin: 639 Springer Science \& Business Media; 1996.

640 [29] Kornacka EM, Przybytniak G, Święszkowski W. The influence of crystallinity on radiation 641 stability of UHMWPE. Radiation Physics and Chemistry. 2013;84:151-6.

642 [30] Ceresoli D, Tosatti E, Scandolo S, Santoro G, Serra S. Trapping of excitons at chemical defects 643 in polyethylene. The Journal of Chemical Physics. 2004;121:6478-84.

644 [31] Wojnárovits L, Luthjens LH, De Leng HC, Hummel A. On the mechanism of alkane S1 decay. 645 Journal of Radioanalytical and Nuclear Chemistry. 1986;101:349-57.

646 [32] Wojnarovits L. Photochemistry and Radiation Chemistry of Liquid Alkanes: Formation and 647 Decay of Low-Energy Excited States. In: Mozumder A, Hatano Y, editors. Charged Particle and 648 Photon Interactions with Matter. Boca Raton: CRC Press; 2004. p. 365-402.

649 [33] Dellonte S, Flamigni L, Barigelletti F, Wojnarovits L, Orlandi G. Temperature dependence of 650 the fluorescence lifetimes of linear alkanes: a correlation with the photodecomposition. The 651 Journal of Physical Chemistry. 1984;88:58-61.

652 [34] Hartley GH, Guillet JE. Photochemistry of Ketone Polymers. I. Studies of Ethylene-Carbon 653 Monoxide Copolymers. Macromolecules. 1968;1:165-70. 